\title{
EVOLUÇÃO TECTÔNICA DO CINTURÃO DOM FELICIANO NO ESCUDO SUL-RIO-GRANDENSE: PARTE II - UMA CONTRIBUIÇÃO A PARTIR DAS ASSINATURAS GEOFÍSICAS
}

\author{
LUÍS ALBERTO DÁ VILA FERNANDES*'**; RUALDO MENEGAT****; ANTÓNIO FLÁVIO UBERTI \\ COSTA ‘ ; EDINEI KOESTER*****; CARLA CRISTINE PORCHER*; ANDREIA TOMMASI******; GUSTAVO \\ KRAEMER $* * * * * ;$ GILBERTO EMÍLIO RAMGRAB***\& EDUARDO CAMOZZATO***
}

\begin{abstract}
RESUMO O reconhecimento de três blocos geofísicos no Escudo Sul-rio-grandense, a partir de técnicas gravimétricas e aeromagnetométricas, permitiu uma reavaliação e teste dos modelos de compartimentação geotectônica propostos a partir do registro geológico para as rochas pré-Cambrianas. Os blocos geofísicos ocidental, central e oriental são separados por importantes descontinuidades gravimétricas e aeromagnetométricas e correspondem às associações de rochas com características petrogenéticas compatíveis e típicas de determinados ambientes geotectônicos. O bloco ocidental constitui-se de duas associações de rochas plutônicas cálcio-alcalinas neoproterozóicas de margem continental ativa, estabelecidas sobre crosta eoproterozóica retrabalhada. Este é delimitado do bloco central pela Sutura de Porto Alegre, uma anomalia gravimétrica e magnetométrica. O bloco central é subdividido em duas porções pela Sutura de Caçapava, uma anomalia aeromagnética. A porção central-leste corresponde a rochas do embasamento eoproterozóico tectonicamente retrabalhado e a central-oeste é formada principalmente por crosta juvenil neoproterozóica. Essa é separada do bloco geofísico oeste pela Sutura de São Gabriel, que delimita o Cráton Rio de La Plata, à oeste, do Cinturão Dom Feliciano, ao qual pertencem os blocos central e leste. Os dados geofísicos permitiram, ainda, não só a definição mais precisa da natureza e limites de algumas das associações petrotectônicas reconhecidas, mas também tornaram possível o teste e a discussão dos modelos de compartimentação tectônica, propostos até o momento para o Escudo Sul-rio-grandense, sob o ponto de vista metodológico e epistemológico.
\end{abstract}

\begin{abstract}
The recognition of three geophysical domains hás permitted a re-evaluation of the geotectonic models proposed for the precambrian rocks of the Sul-rio-grandense shield. The eastern, central and western geophysical domains are separated by important gravimetric and aeromagnetic discontinuities and consist of assemblages of rocks with petrogenetic characteristics of specific tectonic environments. The eastern domain includes two neoproterozoic calc-alkaline plutonic sequences, typical of active margin environments, and developed upon reworked eoproterozoic basement. It is separated from the central domain by the Porto Alegre Suture, which is marked by a gravimetric and aeromagnetic anomaly. The central compartment is sub-di vided into two segments by the Caçapava Suture, marked by an aeromagnetic anomaly. Its central-eastern segment consists of tectonically reworked eoproterozoic basement rocks and the central-western segment is composed of juvenile neoproterozoic crust. It is separated from the western geophysical compartment by the São Gabriel Suture, that is the boundary between the Rio de La Plata Cráton to the west and the Dom Feliciano Belt, to the east. The geophysical data ha vê allowed a more precise definition of the nature and boundaries of some of the petrotectonic assemblages recognised, in addition to making it possible to test and discuss the tectonic models proposed for the Sul-rio-grandense shield from a methodological and epistemological point of view.
\end{abstract}

INTRODUÇÃ̃ Dados geofísicos são atualmente considerados essenciais para a realização de estudos geotectônicos. Levantamentos gravimétricos em escala regional, associados à magnetometria e aos métodos sísmicos, mostraram-se fundamentais no reconhecimento e mapeamento dos limites entre unidades e províncias tectônicas, principalmente as de primeira ordem. O Escudo Canadense constitui-se, provavelmente, no melhor exemplo desta aplicação. Gibb \& Thomas (1976), Gibb et al. (1983) e Thomas et al. (1988) mostraram que as assinaturas gravimétricas nos limites entre diferentes províncias são extremamente similares. Trabalhos semelhantes foram desenvolvidos nas mais diversas regiões: Wellman (1988), Drummond (1988) e White (1988) investigaram a crosta pré-cambriana na Austrália e Subrahmanyam (1978) no Escudo Indiano. Black et al. (1979), De Beer \& Meyer (1983) e Nyblade \& Pollack (1992) aplicaram técnicas de geofisica para o continente africano, enquanto Lesquer et al. (1981) e Haralyi \& Hasui (1982) investigaram a crosta pré-cambriana do leste brasileiro e Elo et al. (1989) e Gáal et al. (1989) utilizaram-se dessas técnicas no Escudo Báltico. Esses estudos tentaram explicar a origem das anomalias gravimétricas detectadas nos limites entre as províncias tectônicas através da justaposição de blocos crustais, com espessuras e densidades diferentes, através de processos colisionais. Outros pesquisadores apresentaram interpretações distintas para as mesmas anomalias. Um exemplo é o trabalho de Gwavava et al. (1992) que, baseado em um forte controle da densidade das rochas, interpretou a anomalia gravimétrica de grande comprimento de onda detectada no Cinturão Limpopo, entre os Crátons Kaapvaal e Zimbabwe, no sul do continente africano, como tendo sido provocada por um adelgaçamento crustal relacionado ao evento de fragmentação do Gondwana. Um terceiro grupo de aplicações de técnicas de geofísica, consiste no estudo de áreas menores, no interior das províncias tectônicas, com enfoque principalmente na sua caracterização geofísica e na modelagem da estruturação das associações petrotectônicas. Utilizando-se essa abordagem, Gupta et al. (1982) e Kehlenbeck \& Cheadle (1989), investigaram as as

\footnotetext{
* CPGq-Depto de Geologia -IG/UFRGS (Ferna@vortex.ufrgs.br)

** Pesquisador do CNPq

*** Serviço Geológico do Brasil (CPRM)

**** Depto de Paleontologia e Estratigrafia -IG/UFRGS

***** Curso de Pós-Graduação em Geociências- IG/UFRGS

$* * * * * *$ Lab. Tectonophysique-Université de Montpellier II (Fr)
} 
subprovíncias Quetico e Wawa e o Greenstone Belt BirchUchi no Escudo Canadense, enquanto que Subrahmanyam \& Verma (1982) aplicaram com sucesso as mesmas no Escudo Indiano e nos terrenos granito-greenstone de Dharwar. Elo et al. (1989), Elo e Korja (1993) desenvolveram estudos semelhantes no Escudo Báltico, distinguindo entre as diversas associações petrotectônicas e as áreas ocupadas pelos granitos rapakivi, respectivamente.

Dados de gravimetria, obtidos no Programa de Levantamentos Geológicos Básicos da CPRM/SUREG-POA, e de aeromagnetometria, levantados através dos projetos Aerogeofísico Camaquã (Jackson 1973) e Extremo Sudeste do Brasil (Anjos \& Mourão 1987), apenas recentemente processados, acompanhados por estudos de detalhe de algumas regiões (eg. Costa et al. 1995a,b), são apresentados e discutidos sob a luz de um modelo geotectônico desenvolvido dentro de um programa de pesquisa elaborado com base nos preceitos da Tectônica de Placas ( $c f$. Parte I desse artigo). Através da análise desses dados, foram definidos domínios geofísicos, caracterizados não apenas pela contituidade do padrão do sinal geofísico, mas também pelas principais descontinuidades reconhecidas, vindo a definir três blocos específicos. No item seguinte, uma compartimentação geotectônica preliminar foi estruturada a partir da compatibilização entre o conjunto dos dados geológicos e geofísicos disponíveis, integrando-os e discutindo as características dos principais blocos geofísicos anteriormente delimitados. O objetivo principal é sistematizar os dados disponíveis, possibilitando a distinção entre os eventos geológicos razoavelmente bem estabelecidos e aqueles que devem ser ainda melhor investigados. Visa, igualmente, o estabelecimento de diretrizes gerais para que estudos mais específicos possam testar as proposições de evolução petrogenética de certas associações de rochas, bem como discutir o seu papel na estruturação do Cinturão Dom Feliciano. Como muitas das rochas responsáveis pela assinatura geofísica são mais jovens do que a estruturação da colagem orogênica inicial (Cinturão Dom Feliciano), a caracterização da geofísica de cada um dos domínios será acompanhada, quando necessário, por um breve comentário acerca da associação de rochas responsável pelo padrão observado, designando-se as mesmas de acordo com a nomenclatura estratigráfica tradicional (cf. Carraro et al. 1974, Santos et al. 1989), por serem, ainda, as mais coerentes com os preceitos da nomenclatura estratigráfica. O papel desempenhado por essas unidades na estruturação da colagem orogênica e suas idades em relação aos eventos responsáveis pela estruturação do Cinturão Dom Feliciano são assuntos da seção seguinte. Encerra a presente contribuição uma sequência de conclusões que procuram aquilatar o impacto das assinaturas geofísicas na proposição de modelos geotectônicos. Além disso, aponta-se a importância da integração de técnicas na proposição de programas de pesquisa capazes de estruturar com clareza modelos testáveis, buscando assim contribuir com o aperfeiçoamento da pesquisa geológica no Rio Grande do Sul.

\footnotetext{
ASSINATURAS GEOFÍSICAS DO ESCUDO SULRIO-GRANDENSE Domínios e descontinuidades gravimetncos Anomalias gravimétricas de extensão regional, separando três domínios distintos, podem ser observadas através da análise da Figura 6. A existência deste padrão geral, foi reconhecida primeiramente por Costa et al. (1989), tendo sido mais recentemente interpretado como representando três blocos crustais distintos (Costa et al. 1995b). Os dados geofísicos presentemente discutidos, além de servirem para confirmar a sistematização anterior, evidenciaram a
}

existência de uma maior complexidade no interior de cada domínio.

O DOMÍNIO GRAVIMÉTRICO LESTE (DGRV E) A análise do mapa gravimétrico na porção leste do escudo (Fig. 1) permite a caracterização de duas áreas distintas; uma ao norte, marcada por um baixo gravimétrico; e, outra, ao sul, identificada por um alto gravimétrico.

Na porção sul dessa região, a presença de um alto gravimétrico com orientação $\mathrm{N} 45^{\circ} \mathrm{W}$, torna complexa a interpretação dos dados gravimétricos, em vista da dificuldade de explicar essa anomalia com base na geologia de superficie. No entanto, a observação de que essa anomalia secciona o baixo gravimétrico relacionado à ZCTDC, sugere que a mesma é uma feição bem mais recente, o que talvez seja confirmado pela sua posição, coincidente com o 'Arco de Rio Grande', de idade mesozóica.

O DOMÍNIO GRAVIMÉTRICO CENTRAL (DGRV C) No domínio gravimétrico central (DGRV C), rochas que fazem parte dos 'grupos' Vacacaí, Porongos, Cerro Mantiqueiras e rochas supracrustais da Sequência Passo Feio que afloram em torno do Complexo Granítico de Caçapava do Sul, além da Fm. Hilário, são responsáveis pelos altos gravimétricos. Tantos os granitóides deformados do complexo granítico de Caçapava como os granitóides orogênicos da Associação de Arco Magmático II (gnaisses Cambaí, cf. Silva $\mathrm{F}^{\mathrm{o}}$ 1984), quanto os pós-tectônicos como os granitos Lavras, Jaguari, Cerro da Cria, São Sepé, Santo Afonso e os do Complexo de Encruzilhada, juntamente com os granitóides pós-tectônicos da região de Encruzilhada do Sul (Serra do Erval, Cachoeira, etc.) são responsáveis pelos baixos gravimétricos relativos.

A Zona de Cisalhamento Transcorrente Dorsal de Canguçu (ZCTDC) é identificada como um baixo gravimétrico cujo eixo converge ao sul coincidindo com a Sutura de Porto Alegre e alcançando a fronteira com o Uruguai ( $c f$. Hallinan et al 1993, Costa et al 1994,1995).

O DOMÍNIO GRAVIMÉTRICO OESTE (DGRV W) O do- mínio gravimétrico oeste (DGRV W) é bastante homogéneo, sendo caracterizado por um alto gravimétrico, e coincide com as rochas de fácies granulito do Complexo Granulítico Santa Maria Chico (Nardi \& Hartmann 1979). É separado das rochas do domínio central por uma forte descontinuidade gravimétrica de direção geral N-S, que se estende para o sul até o Uru- guai, e para o norte, sob os sedimentos Paleozóicos da Bacia do Paraná (cf. Fig. 1). Essa anomalia proeminente, que demar-ca o limite entre os dois domínios, é aqui denominada de Sutu-ra de São Gabriel. No Uruguai essa anomalia geofísica coinci-de com a posição da Falha Cova do Tigre, uma estrutura cujas características e evolução não são muito bem conhecidas.

Domínios e descontinuidades aeromagnetométricas A análise dos dados aeromagnetométricos disponíveis para a porção do escudo à leste do meridiano $54^{\circ}$, permite a identificação de três grandes domínios alongados segundo a direção NE-SW denominados de domínios aeromagnetométricos leste (DAMAG E), central-leste (DAMAG $\mathrm{CE})$ e central-oeste (DAMAG CW) (2). Pelo fato da área dos dados aeromagnetométricos não atingir toda a porção oeste do Escudo Sul-rio-grandense, diferentemente da área abrangida pelos dados gravimétricos, optou-se por não denominar o domínio aeromagnetométrico mais ocidental como sendo domínio oeste, mas sim como domínio aeromagnetométrico 


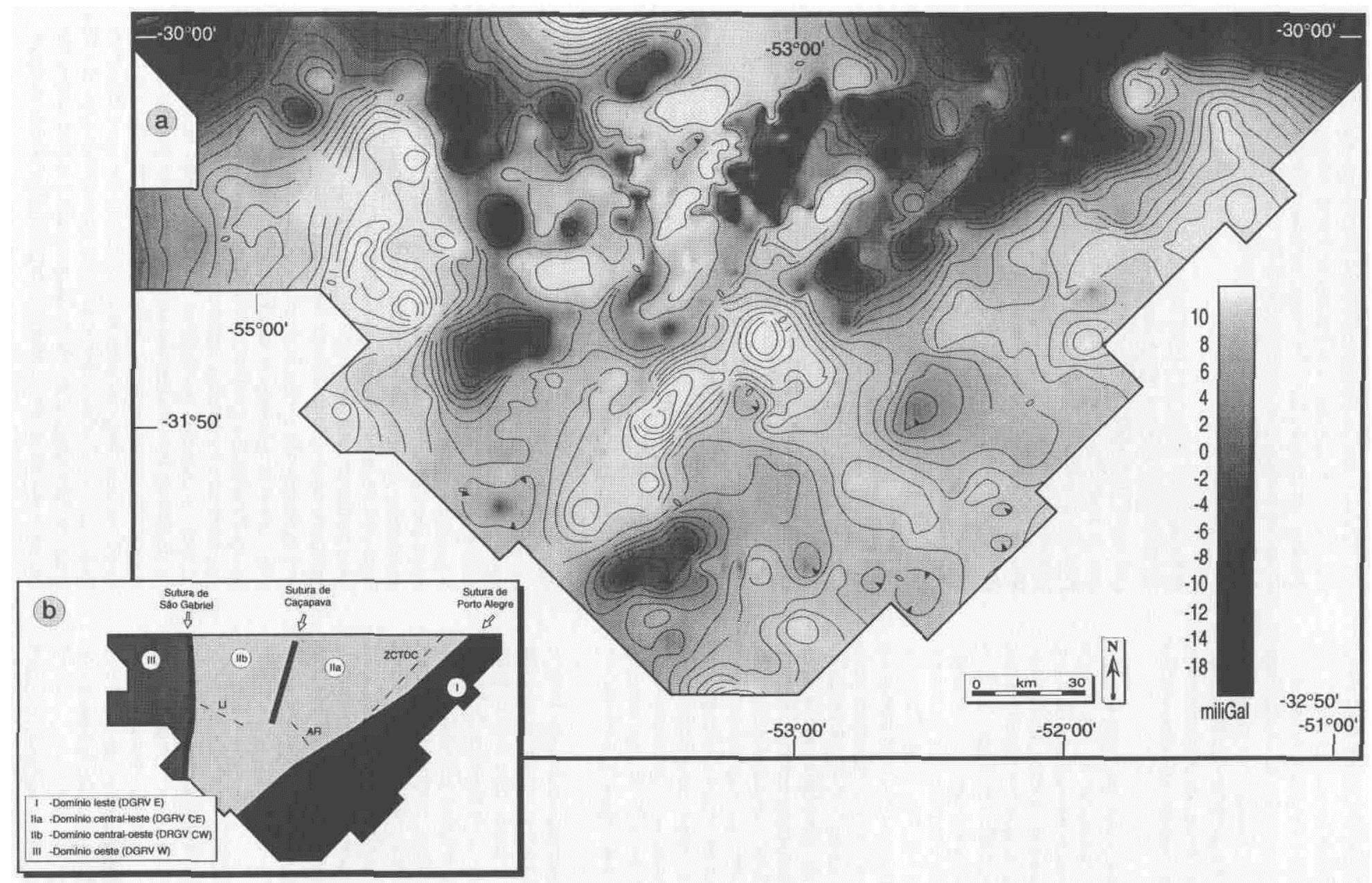

Figura l - Mapa Bouguer do Escudo Sul-rio-grandense (a). Quatro diferentes domínios foram individualizados (b) nesse mapa: I - domínio gravimétrico leste (DGRV E)-IIa - dominio gravimétrico central-leste (DGRV CE); IIb - dominio gravimétrico central-oeste (DGRV CW) e III - domínio gravimétrico oeste (DGRV W) O limite entre esses dominios são marcados por descontinuidades gravimétricas, a Sutura de Porto Alegre, a Sutura de Caçapava e a Sutura de São Gabriel. A primeira separa rochas de um arco magmatico de margem ativa estabelecido sobre uma crosta continental à leste, do embasamento paleoproterozóico. A Sutura de Caçapava separa os gnaisses do embasamento e a cobertura de baixo grau do arco magmático juvenil, que por sua vez, delimita-se, através da Sutura de São Gabriel, com o Cráton do Rio de La Plata (cf. Fig 3) Define-se ainda no mapa gravimétrico o posicionamento da Zona de Cisalhamento Transcorrente Dorsal de Canguçu (ZCTDC), do Lineamento de Ibaré (LI) e das anomalias relacionadas com o Arco de Rio Grande (AR).

Figure 1 -Map of Bouguer anomalies for the Sul-rio-grandense shield. Four main domains were recognised: I- Eastern gravimetric (DGRV E); IIa- Central-eastern gravimetric domain (DGRV CE); 1lb- Central-western gravimetnc domam (DGRV CW) and III- Western gravimetric domain (DGRV CW). Boundaries between these domains are marked by gravimetric discontinuities, the Porto Alegre, Caçapava and São Gabriel suture zones. The Caçapava Suture Zone separates basement gneisses and their cover of supracrustal rocks from the juvenile rodes of the Magmatic Are II Assemblage which is, in turn, separated from the Rio de La Plata Craton
by the São Gabnel Suture Zone (cf. Fig.3). The Dorsal de Canguçce Transcurrent Shear Zone (ZCTDC) and the Ibaré Lineament (LI) are also shown on the gravimetric map, as well as the anomaly related to the Arch of 
central-oeste (DAMAG CW). O domínio situado na área central ficou, portanto, denominado de central-leste (DAMAG $\mathrm{CE}$ ). Desta forma, fez-se coincidir as áreas abrangidas pelos domínios aeromagnetométricos centrais (DAMAG CW e DAMAG CE) com a do domínio gravimétrico central (DGRV C).

O DOMÍNIO AEROMAGNETOMÉTRICO LESTE (DAMAG

E) O domínio aeromagnetométrico leste (DAMAG E) caracteriza-se por um relevo magnético bastante acentuado, evidenciado principalmente pela alta densidade de alinhamentos magnéticos (eixos de anomalias). Esses, são curtos ou alongados, paralelos e ondulados, com direções predominantes entre $\mathrm{N} 70^{\circ} \mathrm{E}$ e E-W. Em algumas áreas, os alinhamentos magnéticos são interceptados por outros, 'de orientação $\mathrm{N} 45^{\circ} \mathrm{E}$.

A geologia desse domínio é composta por um grande volume de granitóides orogênicos deformados do Complexo Gnáissico Piratini (unidade mais joven da Associação de Arco Magmático I), com pequenos xenólitos de rochas supracrustais, que constituem o substrato rochoso que foi afetado pelas zonas de cisalhamento transcorrentes NE ( $c f$. Figs. 5c \& e Fernandes et al. 1992b, Tab. Ia). Enquanto que as anomalias $\mathrm{N} 70^{\circ} \mathrm{E}$ podem representar as direções estruturais da trama principal dessa associação de rochas ( $c f$. Fig. 5 c da Parte I e Tommasi et al. 1992, Costa \& Caldasso 1994), as zonas de cisalhamento transcorrentes parecem ser responsáveis pelo seu deslocamento ao longo das anomalias $\mathrm{N} 45^{\circ} \mathrm{E}$. A intrusão de grandes volumes de granitóides, de afinidade cálcio-alcalina, alto-K e alcalinos tardi- a pós-transcorrência ( $c f$. Fig. 3c da Parte I e Frantz \& Fernandes 1994), aparentemente não afetam o padrão magnético geral. Além disso, diversas intrusões de magmas básicos, de pequenas dimensões, são aparentemente responsáveis pelas anomalias magnéticas intensas, de eixos curtos e formas elípticas. Finalmente, as longas anomalias contínuas e estreitas com direção $\mathrm{N} 70^{\circ} \mathrm{W}$, que atravessam todos os domínios, correspondem a diques de diabásio do Mesozóico e mais jovens.

O limite entre os domínios aeromagnetométricos leste e central-leste é caracterizado por um extenso alinhamento com direção $\mathrm{N} 45^{\circ} \mathrm{E}$, nas porções sul e central, que inflete para $\mathrm{N} 60^{\circ} \mathrm{E}$, na sua porção norte, denominado de Sutura de Porto Alegre. Em termos das compartimentações petrotectônicas identificadas no item 2, o domínio leste corresponderia ao Complexo Canguçce (Santos et al. 1989), "Bloco" Dom Feliciano (Ramgrab et al 1995) e, excluídas as rochas de alto grau metamórfico da região de Encruzilhada do Sul, (Complexo Gnáissico Arroio dos Ratos), que fazem parte do Domínio Central, à Associação de Arco Magmático I (Fernandes et al. 1992a, b).

\section{O DOMÍNIO AEROMAGNETOMÉTRICO CENTRAL-LES-} TE (DAMAG CE) O domínio aeromagnetométrico central-leste (DAMAG CE) é representado por um relevo magnético transparente, pouco acentuado e homogêno. Ë oeste, esse domínio é limitado por um marcante lineamento retilíneo e contínuo, com orientação $\mathrm{N} 35^{\circ} \mathrm{E}$, denominado de Sutura de Caçapava.

Associações de rochas bem definidas em superfície, como as rochas supracrustais da Suíte Metamórfica Porongos e os gnaisses Encantadas, representando o seu embasamento, são as principais unidades desse domínio ( $c f$. Fig. 7 da Parte I). Afloram ainda, na porção NE do mesmo, roof-pendants e xenólitos de metapelitos e mármores da Suíte Metamórfica Várzea do Capivarita, intrudidos pelo Anortosito Capivarita e por granitóides da Complexo Gnáissico Arroio dos Ratos, que, apresentando tramas de alta temperatura orientadas E-W, são retrabalhados pelas zonas de cisalhamento transcorrentes NE (cf. Fig.3 da Parte I e Fernandes et al. 1993). A Zona de Cisalhamento Transcorrente Dorsal de Canguçu (ZCTDC), que secciona esse domínio aeromagnetométrico central-leste, a Zona de Cisalhamento Transcorrente Porto Alegre (ZCTPOA) que secciona o domínio aeromagnetométrico central e por consequência a Sutura de Porto Alegre ( $c f$. Fig. 2, detalhe da porção NE do mapa aeromagnetométrico), bem como as rochas que correspondem às unidades sedimentares da Bacia do Camaquã, apresentam um padrão magnetométrico transparente.

O DOMÍNIO AEROMAGNETOMÉTRICO CENTRAL-OESTE (DAMAG CW) O domínio aeromagnetométrico central-oeste (DAMAG CW), com relevo magnético mais alto do que o anterior, é separado do central por um lineamento $\mathrm{N} 35^{\circ} \mathrm{E}$, que limita as sequências da Bacia do Camaquã, compostas por red beds Eo-paleozóicas, com as rochas supracrustais da Sequência Passo Feio e granitóides da região de Caçapava do Sul. No conjunto, essa região apresenta grandes anomalias alongadas com direções aproximadas $\mathrm{N} 45 \mathrm{jE}$, que estão encurvadas, com tendência ao paralelismo com o lineamento que separa esse domínio do central. A provável causa do padrão magnético na porção norte do domínio $\mathrm{W}$ é a ocorrência de rochas vulcânicas andesíticas shoshoníticas da Fm. Hilário, enquanto que as rochas ultramáficas metamorfisadas da Fm. Cerro Mantiqueiras ( $c f$. Fig. 9c da Parte I), parecem responder pelo padrão exibido na sua porção centrosul. A região ao sul do Lineamento de Ibaré apresenta uma densidade maior de eixos magnéticos levando Costa et al. (1995b) a considerar essa região como um sub-domínio distinto. No entanto, com exceção da maior abundância de anfibolitos à SW do Lineamento de Ibaré, as rochas que afloram nessa área são as mesmas em ambos os lados da zona de falha.

MODELO GEOTECTÔNICO E ASSINATURAS GEOFISICAS O modelo de compartimentação do escudo em domínios apresentado no item 3., acima, embora seja capaz de fornecer uma explicação geológica satisfatória para grande parte dos dados de gravimetria e aeromagnetometria recentemente obtidos, apresenta algumas inconsistências em relação à geologia de superfície, principalmente em termos da distribuição de parte das unidades da colagem orogênica. Esses problemas são discutidos na atual seção, seguindo-se a apresentação da interpretação geológica para cada um dos domínios geofísicos e a discussão do seu significado em termos da compartimentação tectônica adotada (Fig.3). Em função da carência de exposição e dados cronológicos com controle geológico adequado, algumas das principais descontinuidades geofísicas reconhecidas determinam mais precisamente os limites entre as associações petrotectônicas do que os critérios geológicos utilizados. São ainda capazes de demarcar limites internos em associações petrotectônicas compostas, anteriormente definidas em função das suas características petrológicas semelhantes, como é o caso dos granitóides cálcio-alcalinos deformados e metamorfisados em alto grau da Associação de Arco Magmático I e dos xistos atribuídos à Associação de Bacia Marginal, discutidos a seguir.

Bloco geofísico leste: Associação de Arco Magmático 1 Através das assinaturas geofísicas, pode-se individualizar o bloco geofísico leste como sendo composto pelo domínio gravimétrico leste (DGRV E) e pelo domínio aeromagnetométrico leste(DAMAG E). Neste bloco, os gra- 


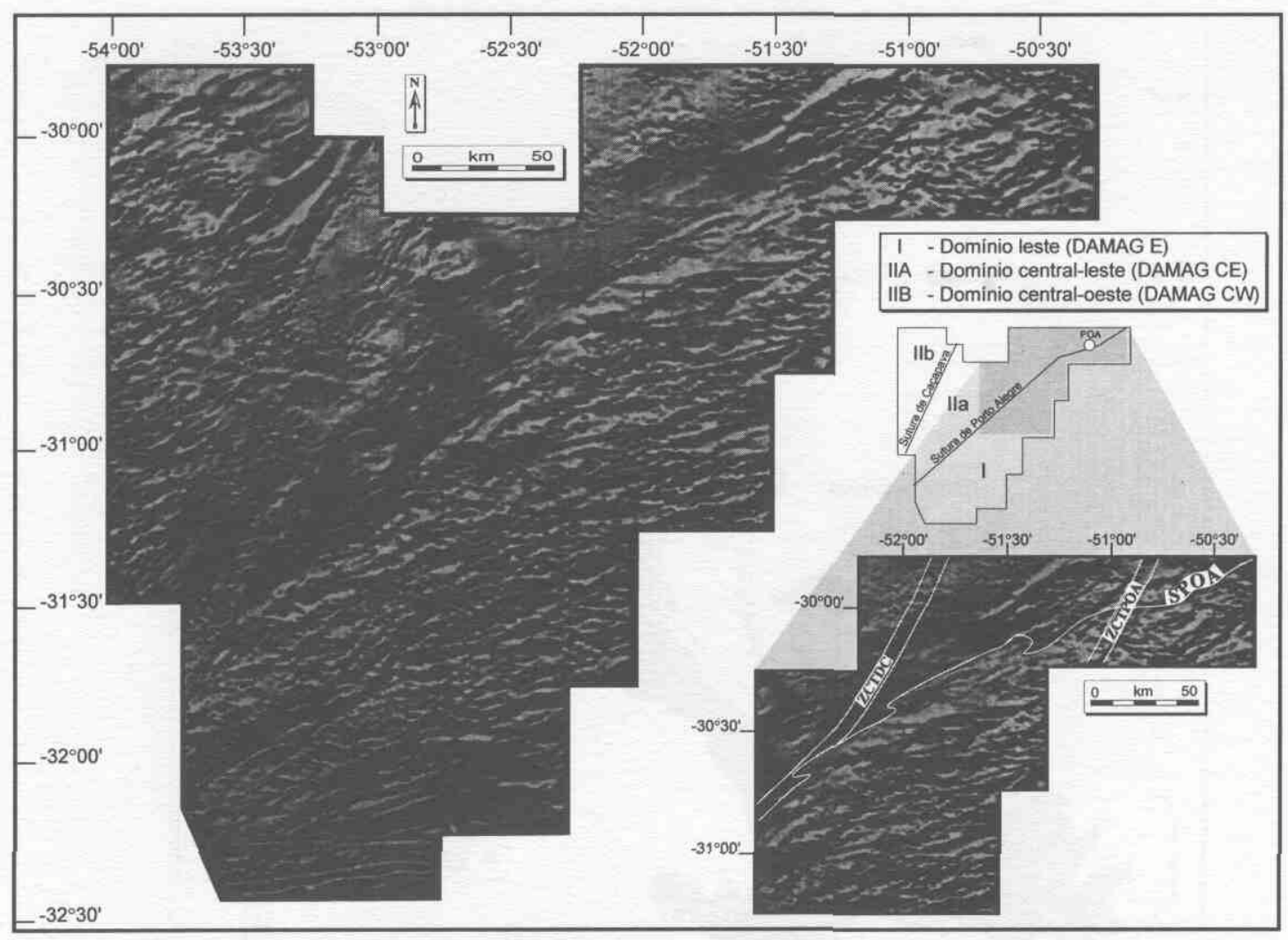

Figura 2 - Mapa aeromagnetométrico de parte do Escudo Sul-rio-grandense. Três diferentes domínios foram individualizados nesse mapa: I - domínio aeromagnetométrico leste (DAMAG E), IIa - domínio aeromagnetométrico central-leste (DAMAG CE) e IIb-domínio aeromagnetométrico central-oeste (DAMAG CW). O limite entre esses domínios são marcados por descontinuidades aeromagnetométricas, a Sutura de Porto Alegre (SPOA) e a Sutura de Caçapava. A primeira separa rochas de um arco magmático de margem ativa estabelecido sobre uma crosta continental à leste, do embasamento paleoproterozóico. A Sutura de Caçapava separa os gnaisses do embasamento e cobertura de baixo grau, do domínio aeromagnetométrico central-leste, do arco magmático onde predomina crosta juvenil, do domínio aeromagnetométrico central-oeste (cf. Fig. 3). No detalhe da porção NE deste mapa, a Zona de Cisalhamento Transcorrente Dorsal de Canguçu (ZCTDC) e a Zona de Cisalhamento Transcorrente Porto Alegre (ZCTPOA) estão demarcadas, e caracterizam-s e por seccionar os blocos geofisicos leste e central-leste (cf. item 4.). Note-se que o mapa aeromagnetométrico, que se estende para oeste somente até o meridiano 54o, não abrange a mesma área do mapa gravimétrico.

Figure 2 - Aeromagnetic map of the central-eastern part of the Sul-rio-grandense Shield. Three different domains were distinguished in this map: I- Eastern aeromagnetic domain (DAMAG E); IIa- central-eastern aeromagnetic domain (DAMAG CE) and Ilb- central-western aeromagnetic domain (DAMAG CW). The boundary between these domains are marked by aeromagnetic discontinuities, the Porto Alegre Suture (SPOA) and the Caçapava Suture. The former separates rocks of an active magmatic are built on continental crust to the East from the paleoproterozoic basement to the West. The Caçapava Suture separates the basement gneisses and their cover of low-grade supracrustal rocks of the central-eastern aeromagnetic domain from the central-eastern aeromagnetic domain, where juvenile crust predominates (cf. Fig.3). The inset shows a detailed view of the north-eastern part of this map shows the Dorsal de Canguçoe (ZCTDC) and the Porto Alegre (ZCTPOA) transcurrent shear zones, both cutting the aeromagnetic domains (cf. Item 4). Note that the aeromagnetic map extends only until the $54^{\circ}$ meridian not covering the same área of the Bouguer map.

nitóides da Associação de Arco Magmático I compõem as principais unidades de rochas. As diferenças das características metamórficas e estruturais entre os segmentos norte (mais antigo) e sul (mais novo) da Associação de Arco Magmático I na região Leste do escudo foram anteriormente explicadas em termos das diferenças das idades destas duas sub-unidades em relação aos episódios tectônicos que afetaram a região (Fernandes et al. 1992b). De acordo com essa interpretação os granitóides cálcio-alcalinos da porção norte teriam sido formados durante um evento magmático anterior aos do sul e subsequentemente afetados por diversos episódios deformacionais, o celtimo dos quais com idades de $723 \pm 13 \mathrm{Ma}(\mathrm{Rb} / \mathrm{Sr})$. Por outro lado, o maior volume de magmas orogênicos da porção sul, mostrando estruturas magmáticas melhor preservadas e metamorfismo e deformação menos intensos teriam sido formados posteriormente, embora os principais eventos magmáticos e metamórfico-deformacionais registrados nes- sas rochas tenham ocorrido durante o Ciclo Orogênico Brasiliano (Fernandes et al. 1992b). Os granodioritos a trondhjemitos mais antigos da porção norte ( $c f$. Fig. 3c da Parte I) representariam os granitóides "cordilheiranos", pré-colisionais, enquanto os granitos cálcio-alcalinos mais jovens da porção sul (cf. Fig. 5c da Parte I) poderiam representar um arco magmático mais jovem e evoluído e, consequentemente, mais doectil em função do fluxo térmico mais elevado dessa porção. Esta interpretação, é aparentemente corroborada pelas diferenças de padrão estrutural e metamórfico entre as duas sub-unidades referidas. Nesse caso, a Sutura de Porto Alegre poderia estar delimitando as rochas de um arco magmático mais novo, com magmatismo bem desenvolvido e apresentando poucos remanescentes do embasamento mais antigo (à SE), com os granitóides cordilheiranos e remanescentes melhor preservados de uma crosta paleoproterozóica (Gnaisses Encantadas) e cobertura de rochas supracrustais à NW. A 


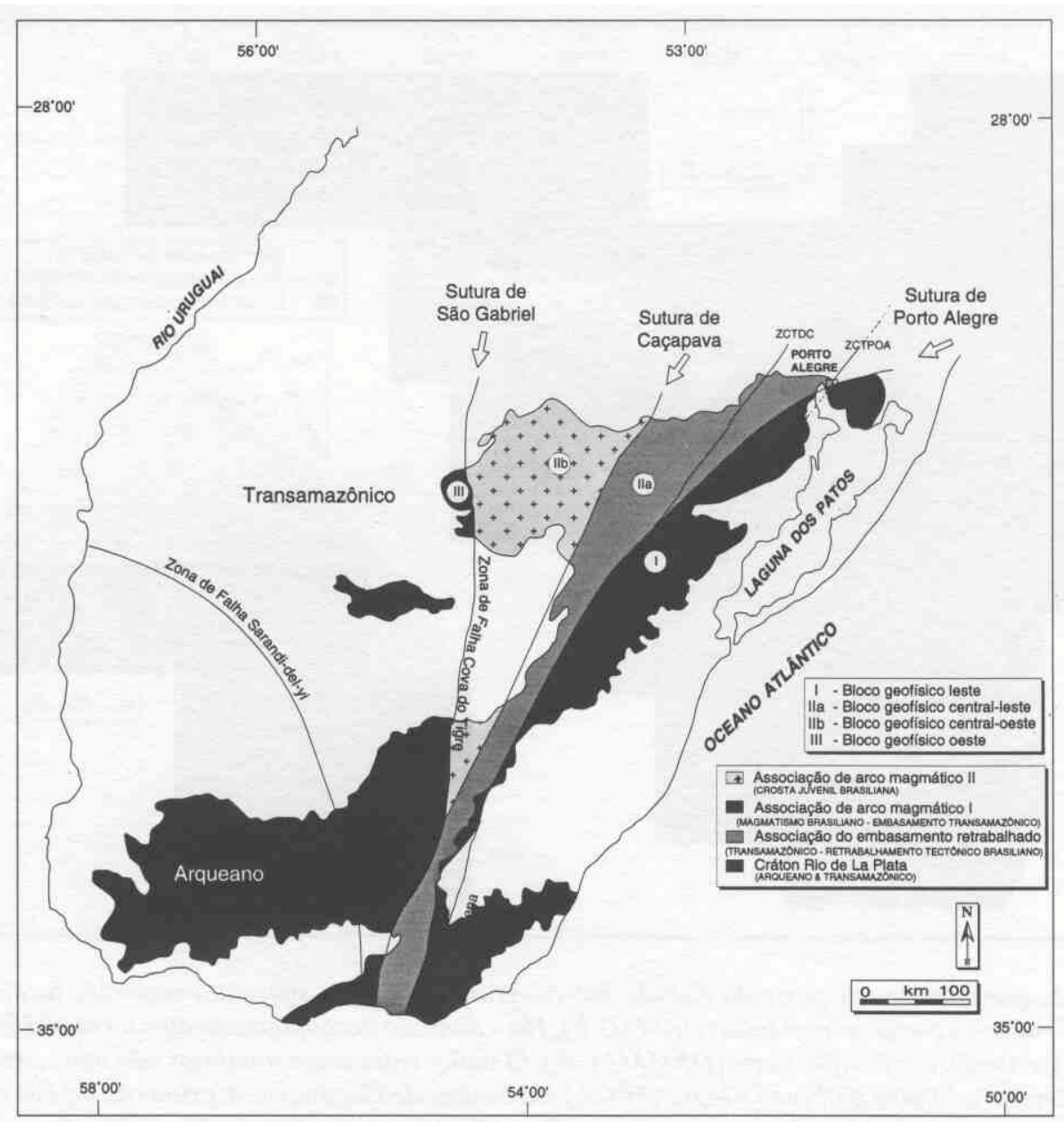

Figura 3 - Compartimentação geotectônica do Escudo Uruguaio-Sul-rio-grandense a partir das assinaturas geofisicas, obtidas com a gravimetria e aeromagnetometria. A. Sutura de São Gabriel observada no mapa Bouguer marca o limite entre o Cráton Rio de La Plata (à W) e o Cinturão Dom Feliciano-CDF (à E). As principais descontinuidades geofisicas entre as associações petrotectônicas do CDF incluem, (de W para E) a Sutura de Caçapava, marcando o limite entre o embasamento neoproterozóico tectonicamente retrabalhado (à E) e a Associação de Arco Magmático II (à W), formada predominantemente por crosta juvenil e remanescentes da crosta oceânica da bacia marginal. A Sutura de Porto Alegre, mais a leste, separa os granitóides cálcico-alcalinos mais novos da Associação de Arco Magmático I (à SE), dos mais antigos da região de Encruzilhada do Sul (à $N W$ ), bem como, do embasamento retrabalhado. As Zona de Cisalhamento Transcorrente Dorsal de Canguçu (ZCTDC) e a Zona de Cisalhamento Transcorrente de Porto Alegre (ZCTPOA) ambas no RS e a Sierra Ballena (Uruguai) são mais jovens do que a estruturação da colagem orogênica (CDF), a primeira encaixando-se na Sutura de Porto Alegre na latitude da cidade de Encruzilhada do Sul (30³0"S-Fig. 3-Parte 1). A compartimentação interna ao Cráton Rio de La Plata entre o Arqueano-Eoproterozóico (linha tracejada) e os limites entre os blocos geofisicos oriental e central do Uruguai foram posicionados a partir de dados da literatura (Hallinan et al. 1993).

Figure 3 - Tectonic compartments of the Uruguayan-Sul-rio-grandense Shield proposed on the basis of gravimetric and aeromagnetic data. The São Gabriel Suture observed in the Bouguer map marks the boundary between the Rio de La Plata Cráton (to the West) and the Dom Feliciano Belt (to the East). The main geophysical discontinuities between the lithotectonic assemblages recognised in the Dom Feliciano Belt include (from W to E) the Caçapava Suture, marking the boundary between the reworked Neoproterozoic basement (to the E) and the Magmatic Are Assemblage II (to the W), the latter composed predominantly by juvenile crust and remnants of the oceanic crust of the marginal basin. The Porto Alegre Suture, to the East, separating the younger calc-alkaline granitoids of the Magmatic Are Assemblage I (to the SE), from the older granitoids of this unit and the associated reworked basement rocks to the West. The Dorsal de Canguçce (ZCTDC) and Porto Alegre (ZCTPOA), as well as the Sierra Ballena transcurrent shear zones are structures younger than the orogenic collage (Dom Feliciano Belt). The former merges into the Porto Alegre Suture at the latitude of the town of Encruzilhada do Sul ( $30^{\circ} 30^{\prime \prime} \mathrm{S}-c f$. Fig. 3 of Part I). Compartments between archaean and Neoproterozoic rocks internai to the Rio de La Plata Cráton and the boundaries between the eastern and central blocks in Uruguay were traced from data of the literature (Hallinan et al. 1993).

colisão final entre o Cráton do Kalahari e a margem continental ativa (Fig.2-Parte I) teria originado a Sutura de Porto Alegre, localizando-se a mesma ao longo da principal descontinuidade reológica entre as duas sub-unidades de granitóides cálcio-alcalinos.

Modelagem em profundidade das anomalias magnetométricas na porção meridional da Sutura de Porto Alegre sugere que a mesma apresenta, nessa região, mergulhos em torno de $70^{\circ}$ para SE (Costa \& Caldasso 1994). Essa evidência, se considerada em conjunto com o padrão de lineações NW-SE, marcando a direção de transporte tectônico durante a deformação de mais alta temperatura que afetou as rochas da porção meridional da AAM I, permite sugerir-se que a Sutura de Porto Alegre marca a zona de colisão entre o arco magmático mais novo, de um lado, e a crosta siálica formada pelos granitóides 
cordilheiranos do Complexo Gnáissico Arroio dos Ratos e as rochas supracrustais de alto grau, de outro.

Nesse contexto, as rochas supracrustais de alto grau da Suíte Metamórfica Várzea do Capivarita (smVC), que constituem os litodemas mais antigos identificados na região ocupada pela Associação de Arco Magmático I seriam representantes de "...um depósito de uma bacia marginal situada entre uma margem continental passiva à oeste, e um arco magmático ativo, à leste." (Ribeiro \& Fantinel 1978) ou como uma sequência mioclinal brasiliana (Fragoso-César et al. 1982, 1986) que, por estar situada na região do arco magmático, teria sofrido metamorfísmo mais intenso do que as suas equivalentes situadas à oeste. Estas oeltimas, no entanto, correspondem às sequências de rochas supracrustais com características estruturais e metamórficas bastante diferentes que recobrem o embasamento paleoproterozóico no bloco geofísico central, mais a oeste ( $c f$. discussão sobre este bloco, a seguir).

A possibilidade de que os granitóides cálcio-alcalinos mais antigos da região de Encruzilhada do Sul e as rochas supracrustais de alto grau (Suíte Metamórfica Várzea do Capivarita) que afloram na porção norte da AAM I (cf. Fig. 3c-Parte I) constituam-se em unidades do embasamento préBrasiliano, representando o substrato para a instalação do arco magmático de margem continental ativa, é uma interpretação alternativa sendo à primeira vista reforçada por dados isotópicos na região leste do escudo (Mantovani et al. 1987, Basei 1985, Chemale et al. 1994, 1995a,b). No entanto essa interpretação é falseada pelas diferenças de características composicionais, estruturais e metamórficas entre estas rochas e os Gnaisses Encantadas, representantes inquestionáveis do embasamento paleoproterozóico na região. Mapeamento litoestrutural delimitou a distância entre os afloramentos de ambas as unidades em pouco mais de quatro quilómetros (UFRGS 1994). Na região mapeada cada uma dessas unidades apresenta características litológicas metamórficas e deformacionais particulares e distintivas, indicando tratarem-se de sequências de rochas diferentes. Assim, a interpretação das rochas supracrustais de alto grau metamórfico (Suíte Metamórfica Várzea do Capivarita) como uma sequência de margem continental passiva, depositada sobre o embasamento paleoproterozóico representado pelos Gnaisses Encantadas é preferível, sendo compatível com as evidências estratigráficas estruturais e metamórficas disponíveis ( $c$. Fernandes et al. 1992b). Durante o fechamento do Oceano Adamastor (Hartnady et al. 1985), pela convergência entre os crátons do Kalahari e Rio de La Plata, essas rochas teriam sido intrudidas pelos granitóides cordilheiranos mais antigos da margem continental ativa (AAM I). O grande volume de granitóides cálcio-alcalinos mais novos da porção sul da AAM I (Fig. $5 \mathrm{c}$-Parte I) teria sido subsequentemente construído sobre este substrato.

As incertezas quanto à natureza da Sutura de Porto Alegre são muitas, mas deve-se ressaltar que na ausência de dados isotópicos com controle geológico adequado, qualquer interpretação baseada na geologia de superfície deve incorporar a evidência estratigráfica de ligação geológica entre os dois blocos geofísicos (leste e central). Esta evidência estratigráfica é fornecida pela presença de xenólitos e roof-pendants das rochas supracrustais de alto grau da Suíte Metamórfica Várzea do Capivarita nos granitóides cálcio-alcalinos das duas subunidades da Associação de Arco Magmático I.

A necessidade de que esta interpretação seja testada através da obtenção de dados geocronológicos capazes de fornecer as idades dos protólitos e dos eventos estruturais e metamórficos que afetaram essas rochas, é evidente. Soma-se a isso a necessidade de investigar em detalhe a Sutura de Porto Alegre sob o ponto de vista estrutural e geofísico, apesar das dificuldades introduzidas pelo posicionamento de granitos sub-alcalinos tardios ao longo desta descontinuidade (e.g. Granito Santanacf. Menegat et al. 1996). No entanto, qualquer interpretação apresentada para esta estrutura deve considerar o fato de que a mesma separa domínios com padrões de anomalias gravimétricas e magnéticas bastante distintos, sugerindo tratar-se a mesma de uma descontinuidade fundamental da colagem orogênica.

\section{Bloco geofísico central: Associações do Emba- samento Retrabalhado, da Bacia Marginal, do Ar- co Magmático II e ofiolitos relacionados o blo-} co geofísico central, identificado através das assinaturas geofísicas, é delimitado, à leste, pela Sutura de Porto Alegre e, à oeste, pela Sutura de São Gabriel, sendo composto pelos domínios aeromagnetométricos central-leste (DAMAG CE) e central-oeste (DAMAG CW) e o domínio gravimétrico central (DGRV C). Esse bloco geofísico central pode ser, ainda, subdividido em dois, o bloco geofísico central-oeste e o bloco geofísico central-leste, cujas assinaturas estão diretamente relacionadas à presença de diferentes associações petrotectônicas. Os Gnaisses Encantadas, da Associação do Embasamento Retrabalhado, e sua cobertura de metassedimentos de baixo grau, atribuídos à Associação da Bacia Marginal, compõem as principais unidades litológicas do bloco geofisico central-leste. De acordo com o modelo adotado, esta região representaria a parte posterior (back-arc) da margem continental ativa, onde estariam preservados os remanescentes do embasamento pré-Brasiliano e da sedimentação da bacia marginal. Interpretações como esta foram apresentadas desde os primeiros modelos plaquistas para a região (Ribeiro \& Fantinel 1978, Jost \& Bitencourt 1980, Fragoso-César 1980, Tommasi \& Fernandes 1990) e com algumas modificações, são capazes de acomodar as evidências geofísicas, como discutido a seguir.

Rochas supracrustais de baixo grau metamórfico, com uma trama composta mostrando uma foliação de baixo ângulo e lineações orientadas NE-SW, ocorrem tanto no bloco geofisico central quanto no oeste. No primeiro, onde predominam sequências de rochas sedimentares maturas e vulcânicas intermediárias a ácidas ( $c f$. Fig. 7d-Parte I), essas rochas são conhecidas como Suíte Metamórfica Porongos (Jost 1981, Porcher \& Fernandes 1990). No segundo (cf. Fig. 5c-Parte I), ocorre uma considerável contribuição de rochas vulcânicas básicas e ultramáficas tectonicamente intercaladas são denominadas (e inadequadamente classificadas como Supergrupo, Grupo, Formação ou Sequência) Vacacaí, Palma, Cambaizinho, Passo Feio (e.g. Jost \& Villwock 1966, Santos et al. 1989 e referências neste celtimo). As tramas de ambas associações, contudo, são semelhantes, caracterizadas por foliações compostas sub-horizontais e lineações de baixo ângulo com direção NE-SW. A principal diferença entre essas rochas é a composição dos seus litodemas, com as sequências mais diferenciadas e maturas que ocorrem no bloco geofísico centralleste, separadas das mais básicas, que ocorrem no bloco geofísico central-oeste, pela Sutura de Caçapava. As sequências de rochas supracrustais que ocorre no domínio geofísico central-oeste, embora espacialmente justapostas à primeira, sofreram a deformação registrada nas rochas da AAM II e nos remanescentes da crosta oceânica da bacia marginal (Associação Ofiolito-Mélange sensu Tommasi \& Fernandes 1990, Fernandes et al. 1992a). Nesse contexto, a interpretação de que a Sutura de Caçapava marca o limite entre as unidades depositadas sobre a crosta siálica do embasamento paleoproterozóico do bloco geofísico central e as que recobriam a 
crosta oceânica à oeste, deve ser considerada. A referida sutura estaria demarcando, assim, muito mais um limite relacionado ao embasamento do que uma simples descontinuidade das rochas supracrustais em superfície.

A principal dificuldade de interpretação dessas unidades de rochas supracrustais do bloco geofísico central-leste e centraloeste, que se constituem em sequências representativas da bacia marginal, como acima referido, é o padrão de deformação e grau de metamorfismo apresentados pelas mesmas. As direções de transporte tectônico predominantemente NESW (Porcher \& Fernandes 1990) e o grau metamórfico da fácies anfibolito a xisto verde que apresentam (Jost 1982, Hartmann et al. 1990, Porcher et al. 1995) são incompatíveis com os apresentados pelas rochas da Associações de Arco Magmático I e II, que sofreram as deformações colisionais com transporte tectônico transversal ao alongamento do orógeno $(\mathrm{E}-\mathrm{W})$ sob condições metamórficas de fácies anfibolito superior a granulito (Frantz et al. 1982, Fernandes et al. 1992a). O mesmo pode ser afirmado em relação à correlação entre esses xistos e as rochas supracrustais de alto grau da Suíte Metamórfica Várzea do Capivarita, que ocorrem no domínio aeromagnetométrico central-leste ( $c f$. Fernandes \& Frantz 1994). Desse modo, a não ser que a trama exibida pelas rochas supracrustais de baixo grau seja produto de retrabalhamento responsável pela obliteração total do registro de metamorfismo e deformação anteriores, algo bastante improvável, considerando-se a grande quantidade de dados petrográficos disponíveis para todas estas sequências e dos estruturais para as do domínio central (Porcher 1992), deve-se estar preparado para admitir que essas associações de rochas são mais novas do que a estruturação da colagem orogênica inicial (CDF). Nesse oeltimo caso, as sequências de baixo grau teriam sido depositadas discordantemente sobre um substrato representado pela colagem das associações petrotectônicas anteriormente descritas. Embora não tenham sido encontradas evidências de uma discordância entre essas unidades no Escudo Sul-rio-grandense, talvez em função da intensa deformação sofrida pelas mesmas (e.g. Porcher \& Fernandes 1990, Remus 1990), esta poderia ser representada por paraconglomerados oligomíticos mapeados na região da Mina Bossoroca (bloco geofísico central-oeste), que contém seixos de granitos com idade de $753 \pm 2 \mathrm{Ma}$ (U/Pb em zircão-Machado et al. 1990). Outras evidências que favorecem esta oeltima interpretação são fornecidas pela correlação dessas rochas com sequências com melhor exposição, mas extremamente semelhantes em termos de litodemas e características metamórfico-deformacionais no Cinturão Kaoko da Namíbia, onde com base na distribuição e características das fácies sedimentares, estas rochas são interpretadas como depositadas em grabens alongados N-S estabelecidos sobre um embasamento siálico "mais antigo" (Dürr \& Dingeldey 1996).

Os granitóides da Associação de Arco Magmático II (AAM II), conforme Figura 9c da Parte.I, tectonicamente intercalados com remanescentes da crosta oceânica e sedimentos da bacia marginal, compõem outra das principais unidade de rochas da colagem orogênica no bloco geofísico central-oeste. Com exceção dos fragmentos de rochas ultramáficas e supracrustais, a maior parte desse bloco é caracterizada por um baixo gravimétrico representando a assinatura dos granitóides cálcio-alcalinos orogênicos (gnaisses Cambai, cf. Silva P 1984).

As idades arqueanas recentemente obtidas para zircões em granitóides deformados no limite oriental do domínio geofísico central-leste (Remus et al. 1995) admite a interpretação alternativa de que a rocha de onde foram extraídos os zircões constitui-se numa porção do embasamento tectonicamente posicionada. No entanto as características dessas rochas su- gerem que as mesmas constituem-se em porções dos granitóides do Complexo Granítico de Caçapava do Sul (Nardi \& Bitencourt 1989, Fernandes et al 1992a). A interpretação de que os zircões são herdados, além de mais simples, estaria de acordo com a recentemente apresentada por Leite (1995) a partir das características de zircões com idades semelhantes $(2.39 \mathrm{Ga})$ que ocorrem nestas mesmas rochas. Seria ainda compatível com a presença de rochas do embasamento preBrasiliano na região, reforçando a sugestão de que as rochas da AAM II foram originadas num ambiente de margem continental ativa (Tommasi \& Fernandes 1990, Kraemer et $a l, 1995)$, não se tratando, portanto, de uma associação de rochas formadas num ambiente do tipo arco magmático intraoceânico (Fragoso-César et al. 1994)

\section{Bloco geofísico oeste: Cráton do Rio de La Plata}

O bloco geofísico oeste, delimitado do central pela Sutura de São Gabriel, pode ser reconhecido através da assinatura do domínio gravimétrico oeste. A região ocupada pelo alto gravimétrico à oeste das unidades da AAM II, pertencentes ao bloco geofísico central-oeste, caracteriza-se por apresentar uma descontinuidade orientada N-S, cuja existência foi anteriormente especulada por Ramos (1988) e também reconhecida por Costa et al (1989). Essa estrutura, aqui denominada de Sutura de São Gabriel, é interpretada como sendo o limite entre o Cráton Rio de La Plata à oeste, e as rochas juvenis da AAM II do Cinturão Dom Feliciano, à leste ( $c f$. Fig.3). A posição do baixo gravimétrico em relação à zona de sutura pode ser interpretada, de acordo com uma analogia com os resultados de Gibb \& Thomas (1976), como sugestiva da polaridade da subducção com mergulho para oeste (cf. Fig.2Parte I) reforçando a sugestão de Tommasi \& Fernandes (1990) e em desacordo com a proposição de Fragoso-César et al. (1995) e Chemale et al. (1995b).

Finalmente, as direções E-W de transporte tectônico (ortogonais à orientação da Sutura de São Gabriel), exibidas por essas rochas na região de Lavras do Sul (Fig. 9c-Parte I), indicam a possibilidade de uma colisão frontal com o Cráton Rio de La Plata, durante a incorporação das rochas da AAM II à colagem orogênica (cf. Costa et al. 1995b, Kraemer et al. 1995).

CONCLUSÕES: O IMPACTO DAS ASSINATURAS GEOFISICAS O emprego de técnicas gravimétricas e aeromagnetométricas possibilitou a identificação de três importantes blocos geofísicos no Escudo Sul-rio-grandense, denominados de bloco geofísico leste, bloco geofísico central (subdividido nos blocos geofísicos central-leste e central'oeste) e bloco geofísico oeste. A delimitação dos blocos foi estabelecida pelo reconhecimento da existência de importantes anomalias geofísicas, a saber: a Sutura de Porto Alegre, que delimita o bloco leste do bloco central, reconhecida tanto pelas técnicas gravimétricas como pelas aeromagnetométricas, a Sutura de São Gabriel, que delimita o bloco central do oeste, reconhecida de forma inédita pelos dados gravimétricos. Além destas, a Sutura de Caçapava, uma anomalia aeromagnetométrica, é quem demarca as duas sub-unidades do bloco geofísico central.

A delimitação desses blocos geofísicos produz um impacto no estabelecimento dos modelos geotectônicos relacionado à metodologia de teste de modelos. Neste caso, ao promover-se uma integração dos dados geofísicos com os tectono-estruturais, petrológicos e geocronológicos, em termos de uma comparação entre a compartimentação identificada pelas associações petrotectônicas e aquela reconhecida pela assinatura geofísica, acaba-se por checar a consistência de ambos. $\mathrm{O}$ 
resultado dá-se tanto em termos da precisão na identificação das anomalias geofísicas que delimitam os diferentes blocos, como na qualificação do grau de certeza do significado das associações petrotectônicas, resultando em rigor metodológico para ambos. Isto quer dizer, por exemplo, que os altos gravimétricos descritos no bloco geofísico central-leste do Escudo Sul-rio-grandense não são correlacionáveis com os altos gravimétricos reconhecidos ao norte do mesmo cinturão, no escudo catarinense. Enquanto que esses se devem à existência de rochas granulíticas, aqueles se devem à existência de rochas supracrustais. Considerações que postulam que, de qualquer forma, sob as rochas supracrustais estão as rochas granulíticas que geram o alto gravimétrico, são refutadas pelo fato de que as supracrustais são suficientes para gerar os padrões gravimétricos encontrados ( $c f$. Costa 1997). Além disso, devido à presença de intercalações tectônicas entre o embasamento e a cobertura (rochas supracrustais) nessa região, a natureza do embasamento é bem conhecida, tratandose de ortogneisses eoproterozóicos. Por outro lado, a definição da Sutura de São Gabriel como a mais importante descontinuidade geofísica do Escudo, aumenta o grau de certeza na consideração de que os blocos central e leste façam parte de uma mesma colagem orogênica.

Para o Escudo Sul-rio-grandense, o presente trabalho apontou uma delimitação de blocos tectônicos com maior grau de precisão e certeza do que até então havia sido proposto. A sutura de São Gabriel delimita o Cráton do Rio de La Plata, à oeste, do Cinturão Dom Feliciano, que se estende nas porções central e leste. As associações petrotectônicas de todo este compartimento podem, então, ser consideradas geneticamente relacionadas a um evento de estruturação de uma colagem orogênica com seus sucessivos estágio evolutivos.

Um novo elenco de questões passam agora a merecer a atenção deste programa de pesquisas, revitalizando-o. Algumas delas referem-se à necessidade de precisar-se as assinaturas geofísicas junto às anomalias identificadas e no interior de alguns dos blocos, como a parte sul do bloco geofísico leste. Coincidentemente, há também uma insuficiência de dados geológicos nesta mesma região. Estudos petrológicos e estruturais deverão ser intensificados na porção norte da Sutura de Porto Alegre, de modo a melhorar o entendimento sobre a disposição e relações entre as rochas da Associação do Arco Magmático I, no bloco geofísico centro-leste. Todos esses elementos, demonstram a fertilidade de um programa de pesquisa do tipo plaquista, tanto em termos metodológicos, como substantivos.

Agradecimentos Os autores agradecem ao $\mathrm{CNPq}$ pela concessão de bolsas de Pesquisa (Proc.n 200.858/82), Pósgraduação e auxílios e, ao Instituto de Geociências/ UFRGS pelo apoio logístico durante os Trabalhos de Graduação (1988-1994), que resultaram na realização de alguns dos mapas apresentados. Agradecemos, ainda, aos bolsistas Vilmar R. da Silva, pelo trabalho gráfico de grande parte das figuras, Leondres de Oliveira e Luciana Félix, pelo auxílio com a lista de referências bilbiográficas. Aos Professores B.B. de Brito-Neves e H. Jost agradecemos, respectivamente, o incentivo à apresentação do trabalho e o auxílio com a editoração do mesmo, apesar da exiguidade dos prazos.

\section{REFERÊNCIAS}

ANJOS, I.L.S. \& MOURÃO, L.M. 1987. Projeto Extremo Sudoeste do Brasil. Relatório Final. Vol. I. CPRM

B ASEI, M.A.S. 1985. O Cinturão Dom Feliciano em Santa Catarina. São Paulo. 196p. (Tese de doutorado em Geociências, Universidade de São Paulo).

BLACK, R.; CABY, R.; BAYER, R.;FABRE, J.; LESQUER, A. 1979. Evidence for late Precambrian plate teetonics in West Âfrica. Nature, 278.

CARRARO, C.C.; GAMERMANN, N.; EICK, N.C.; BORTOLUZZI, C.A.; JOST, H.; PINTO, J.F. 1974. Mapa Geológico do Estado do Rio Grande do Sul. UFRGS. Série Mapas. Mapa 8.

CHEMALE JR. F.; GRESSE, P.; DA SILVA, L.C.; HARTMANN, L.A.; WALRAVEN, F. 1995b. Correlação geológica entre as unidades Brasilianas e Panafricanas do Sul do Brasil e Á frica do Sul IN. SIMPÓSIO SULBRASILE1RO DE GEOLOGIA, 6, Encontro de Geologia do Cone Sul, 1. Porto Alegre, 1995. Atas... Porto Alegre, SBG. p. 13-16.

CHEMALE JR. F.; GRESSE, P.; DA SILVA, L.C.; HARTMANN, L.A.; WALRAVEN, F. 1995b. Correlação geológica entre as unidades Brasilianas e Panafricanas do Sul do Brasil e África do Sul. IN: SIMPÓSIO SULBRASILEIRO DE GEOLOGIA, 6, Encontro de Geologia do Cone Sul, 1. Porto Alegre, 1995. Atas... Porto Alegre, SBG. p. 13-16.

CHEMALE JR., F.; HARTMANN, L.A.; BABINSKI, M.; WILDNER, W.; VAN SCHMUS, W.R. 1994. Evolução tectônica do bloco São Gabriel. IN: Congresso Brasileiro de Geologia, 38. Balneário Camboriú, 1994. Boletim de Resumos Expandidos... Balneário Camboriú, SBG. v.l, p.232-233.

CHEMALE JR., F.; HARTMANN, L.A.; DA SILVA, L.C. 1995a. Stratigraphy and Tectonism of Precambriam to early Paleozoic units in Southern Brazil and Uruguay. Acta Geológica Leopoldênsia, 44:1-111.

COSTA A.F.U. \& CALDASSO, A.L.S. 1994. Padrões do campo magnético aplicados à geologia estrutural na região de Pinheiro Machado-RS. IN: CONGRESSO BRASILEIRO DE GEOLOGIA, 38. Balneário Camboriú, 1994. Boletim de Resumos Expandidos... Balneário Camboriú.SBG. v.2, p.31-32.

COSTA, A.F.U. 1997. Modelagem geofisica da estruturação das associações petrotectônicas do Escudo Sul-rio-grandense. Porto Alegre. 274 p. (Tese de Doutorado, Universidade Federal do Rio Grande do Sul).

COSTA, A.F.U; FERNANDES, L.A.D; MAGRO, F.H.S : NADAL, C.A. FÉLIX, L.M. 1995. Modelagem gravimétrica dos granitóides sintectônicos à Zona de Cisalhamento Transcorrente Dorsal de Canguçce. Revista Brasileira de Geofisica, (submetido).

COSTA, A.F.U.; FERNANDES, L.A.D.; MAGRO, F.H.S.; NADAL, C.A.; FÉLIX, L.M. 1994. Modelamento Gravimétrico da Zona de Cisalhamento Dorsal de Canguçoe. IN: CONGRESSO BRASILEIRO DE GEOLOGIA, 38. Balneário Camboriú, 1994. Boletim de Resumos Expandidos... Balneário Camborice, SBG. v.2, p.28-30.
COSTA, A.F.U. RAMGRAB, G.E; CAMOZZATO, E. 1989. Contribuicão da geofisica (gravimetria/magnetometria) à compartimentação do Escudo Sulrio-grandense. IN: Simpósio Sul-brasileiro de Geologia, 4. Porto Alegre, 1989. Anais... Porto Alegre, SBG, (inédito).

COSTA AFU · RAMGRAB, GE - FERNANDES, L A.D - CAMOZZATO, E 1995. Compartimentação tectônica das associações de rochas pré-cambrianas do Escudo Sul-rio-grandense baseada em dados de magnetometria e gravimetria. IN: Simpósio Nacional de Estudos Tectônicos, 5. Gramado, 1995. Boletim de resumos Expandidos... Gramado, SBG. p.236-238.

DE BEER, J. H. \& MEYER, R. 1983. Geoelectrical and gravitational characteristics of the Namaqua-Natal Mobile Belt and its boundaries. Geological Society of South Africa. Special Publication, 10: 91-100.

DRUMMOND, B. J. 1988. A review of crust/upper mantle structure in the precambrian áreas of Austrália and implications for precambrian crustal evolution. Precambrian Research. 40/41:101-116.

DURR, S.B. \& DINGELDEY, D.P. 1996. The Kaoko belt (Namíbia): Part of a late Neoproterozoic continental-scale strike-slip system. Geology, 24:503506.

ELO, S. \& KORJA, A. 1993. Geophysical interpretation of the crustal and upper mantle structure in the Wiborg rapakivi granite área, southeastern Finland. Precambrian Research, 64: 273-288.

ELO, S. LANNE, E., RUOTOISTENMÀKI, T. \& SINDRE, A. 1989. Interpretation of gravity anomalies along the POLAR Profile in the northern Baltic Shield. Tectonophysics, 162: 135-150.

FERNANDES, L.A.D. \& FRANTZ, J.C. 1994. Evolution and mineral potential of the Dom Feliciano Belt in southern Brazil IN: CONGRESSO BRASILEIRO DE GEOLOGIA, 38. Balneário Camborice, 1994. Boletim de Resumos Expandidos... Balneário Camborioe, SBG. v.l, p.622-623.

FERNANDES, L.A.D.; TOMMASI, A.; PORCHER, C.C. 1992a. Deformation Patterns in the Southern Brazilian Branch of the Pan-African Dom Feliciano Belt. Journal of South American Earth Sciences, 5:77-96.

FERNANDES, L.A.D.; TOMMASI, A.; PORCHER, C.C.; KOESTER, E.; KRAEMER, G.; SCHERER, C.M.; MENEGAT, R. 1992b. Granitóides Precoces do Cinturão Dom Feliciano: Caracterização Geoquímica e Discussão Estratigráfica. Pesquisas, 19 (2): 197-218.

FERNANDES, L.A.D.; TOMMASI, A; VAUCHEZ, A.; PORCHER, C.C.; MENEGAT, R.; KOESTER, E. 1993. Zona de Cisalhamento transcorrente Dorsal de Canguçu: Caracterização e importância na compartimentação tectônica do Cinturão Dom Feliciano. Revista Brasileira de Geociências, 23(2): $1-10$.

FRAGOSO-CÉS AR, A.R.S. 1980.0 Cráton do Rio de La Plata e o Cinturão Dom Feliciano no Escudo Uruguaio Sul-riograndense. IN: CONGRESSO BRASILEIRO DE GEOLOGIA, 31. Balneário de Camboriú, 1980. Anais... Balneário de Camboriú, SBG. v.5, p.2879-2892. 
FRAGOSO-CÉSAR, A.R.S.; FIGUEIREDO, M.C.H.; SOLIANI JR., E.; FACCINI, U.F. 1986.0 Batólito Pelotas (Proterozóico Superior/ Eo-Paleozóico) no Escudo do Rio Grande do Sul. IN: CONGRESSO BRASILEIRO DE GEOLOGIA, 38. Goiânia, 1986. Anais... Goiânia, SBG. v.3, p.1322-1342.

FRAGOSO-CÉSAR, A.R.S.; LAVINA, E.L.; PAIM, P.S.; FACCINI, U.F. 1984 A antefossa molássica do cinturão Dom Feliciano no estado do Rio Grande do Sul. IN: CONGRESSO BRASILEIRO DE GEOLOGIA, 33. Rio de Janeiro, 1984. Anais... Rio de Janeiro, Sbg. v.7, p.3272-3283.

FRAGOSO-CÉSAR, A.R.S.; MACHADO, R.; WERNICK, E.; MCREATH, I.; PHILLIP, R.P.; S ALLET, R.; ENDO, I.; MELLO, F.M.; ALMEIDA, T.R.I.; SAYEG, H.S.; FAMBRINI, G.L.; SILVA Fo, W.F.; DEHLER, N.M.; TEIXEIRA, A.L. 1995. The Braziliania Plate, the Western Paranaides and the Eastern Atlantides and África model for the Neoproterozoic Tectonic collage of Southeastern South America. IN: Simpósio Sul-brasileiro de Geologia, 6, Encontro de Geologia do Cone Sul, 1. Porto Alegre, 1995. Atas... Porto Alegre, SBG. p.20-25.

FRAGOSO-CESAR, A.R.S.; WERNICK, E.; SOLIANI JR., E. 1982. Evolução geotectônica do Cinturão Dom Feliciano - uma contribuicão através da aplicacão do modelo de Tectônica de Placas. IN: CONGRESSO BRASILEIRO DE GEOLOGIA, 32. Salvador, 1982: Anais... Salvador, SBG. v.1, p.13-23.

FRANTZ, J.C. \& FERNANDES, L.A.D. 1994. "GranitóidesTardi- aPós-orogênicos do Ciclo Brasiliano no Cinturão Dom Feliciano-RS". IN: CONGRESSO BRASILEIRO DE GEOLOGIA, 38. Balneário de Camboriú, 1994. Boletim de Resumos Expandidos... Balneário de Camborice, SBG. v.í, p.150-152

GAAL, G.; BERTHELSEN, A.; GORBATSCHEV, R.; KESOLA, R.; LEHTONEN, M. I.; MARKER, M.; RAASE, P. 1989. Structure and composition of the Precambrian crust along the POLAR Profile in the northern Baltic Shield. IN: FREEMAN, R., VON KNORRING, M., KORHONEN, H., LUND, C., ST. MUELLER. eds. The European Geotraverse, PartS: The POLAR Profile. Tectonophysics, 162: 1-25.Bay, Ontario. Canadian Journal Earth Sciences. 27:187-199.

GIBB, R.A.; THOMAS, M.D.; LAPOINTE, P.L.; MUKHOPADHYAY, M. 1983. Geophysics of proposed Proterozoic sutures in Canada. . Precambrian Research, 19: 349-384.

GIBBS, R.A. \& THOMAS, M.D. 1976. Gravity signature of fóssil plate boundaries in the Canadian Shield. Nature, 262(15): 199-200.

GUPTA, V. K.; THURSTON, P. C.; DUSANOWSKYJ, T. H. 1982. Constraints upon models of greenstone belt evolution by gravity modelling, Birch-Uchi greenstone belt, northern Ontario. Precambrian Research, 16: 233-255.

GWAVAVA, O., SWAIN, C. J., PODMORE, F. \& FAIRHEAD, J. D., 1992. Evidence of crusta! thinning beneath the Limpopo Belt and Lebombo monocline of southern África based on regional gravity studies and implications for the reconstruction of Gondwana. IN: VON FRESE, R.R.B. \& TAYLOR, P.T. eds. Lithosferic Analysis of Magnetic and Related Geophysical Anomalies. Tectonophysics, 212:1-20.

HALLINAN, S; MANTOVANI, M; SHUKOVSKY, W; BRAGGION JR, I. 1993. Estrutura do Escudo Sul-brasileiro: Uma revisão através de dados gravimétricos e magnetométricos. Revista Brasileira de Geociências, 23(3):201-214.

HARALYI, N. L. E. \& HASUI, Y. 1982. The gravimetric information and the archean-proterozoic structural framework of eastern Brazil.. Revista Brasileira de Geociências, 12(2): 160.

HARTMANN, L.A.; TINDLE, A.; BITENCOURT, M.F.A.S. 1990. O metamorfismo de fácies anfibolito no complexo metamórfico Passo Feio, RS, com base em química dos minerais. Pesquisas, 17(1-2):62-71.

HARTNADY, C.; JOUBERT, P.; STONE, C. 1985. Proterzoic crustal evolution in Southwestern África. Episodes, 48(4):236-244.

JACKSON, V.N.; RAMOS. V.A.; TERRY, S.A.; ZUZEK, A.B. 1973. Projeto Aerofisico Camaquã- Estado do Rio Grande do Sul. TEXAS INSTRUMENTOS DO BRASIL LTDA. Conv. DNPM-CPRM/CNEN-CPRM. I; II; III e IV, 224p., mapas.

JOST, H. \& BITENCOURT, M.F.A.S. 1980. Estratigrafia e tectônica de uma fração da Faixa de Dobramentos Tijucas no Rio Grande do Sul. Acta Geológica Leopoldensia, 15:27-60.

JOST, H. 1981. Geology and metallogeny ofthe Santana da Boa Vista Region, Southern Brazil. Georgia. 208p. (Doctor of Philosophy Thesis, University of Georgia)

JOST, H. 1982. Condições do metamorfismo regional de uma parte da faixa de dobramentos de Tijucas no Rio Grande do Sul. Acta Geológica Leopoldensia, 6:3-32.

JOST, H.\& VILLWOCK, J.A. 1966. Contribuição à estratigrafia do Pré-Cambriano no Rio Grande do Sul. Notas e Estudos. Escola de Geologia, UFRGS, Porto Alegre, 1(1): 13-26.

KEHLENBECK, M. M. \& CHEADLE S. P., 1989. Structural cross sections based on gravity survey of parts of the Quetico and Wawa subprovinces near Thunder Bay, Ontario. Canadian Journal Earth Sciences. 27:187-199.

KRAEMER, G.; FERNANDES, L.A.D.; KOESTER,E.; SOLIANI JR., E. NARDI, L.V.S. 1995. Acresção juvenil brasiliana na porção oeste do Escudo Sul-rio-grandense: A Suíte Ortometamórfica Arroio Imbicuí. IN: SIMPÓSIO NACIONAL DE ESTUDOS TECTÔNICOS, 5. Gramado, 1995. Boletim de resumos expandidos... Gramado, SBG. p.50-51.

LEITE, J.A.D.; MACNAUGHTON, N.J.; HARTMANN, L.A.; CHEMALE JR., F. 1995. Age and tectonic setting of metabasalts and metagranitoids from the Cerro Mantiqueiras region: Evidences from shrimp U/pb zircon dating and $\mathrm{pb} / \mathrm{pb}$ isotopes. IN: SIMPÓSIO NACIONAL DE ESTUDOS TECTÔNICOS, 5. Gramado, 1995. Boletim de resumos expandidos... Gramado, SBG. p.389-390.
LESQUER, A.; ALMEIDA, F. F. M.; DAVINO, A.; LACHAUD J. C.; MAILLARD P. 1981. Signifícation structurale dês anomalies gravimetriques de Ia partie sud du Cráton de São Francisco (Bresil). Tectonophysics, 76:273-293.

MACHADO, N.; KOPPE, J.C.; HARTMANN, L.A. 1990. A late proterozoic U/Pb age for the Bossoroca Belt, RS, Brazil. Journal of Earth American Sciences, 3(2/3):87-90.

MANTOVANI, M.S.M.; HAWKESWORTH, C.J.; BASEI, M.A.S. 1987. Nd and $\mathrm{Pb}$ isotope studies bearing on the crustal evolution of Southeastern Brazil. Revista Brasileira de Geociências, 17:263-268.

MENEGAT, R.; Koester, E.; Kraemer, G.; Scherer, C.M.S.\& Fernandes, L.A.D. 1996. Mapa Geológico do Município de Porto Alegre. Prefeitura Municipal de Porto Alegre e Universidade Federal do Rio Grande do Sul, Porto Alegre (no prelo).

NARDI, L.V.S. \& BITENCOURT, M.F.A.S. 1989. Geologia, petrologia e geoquímica do Complexo Granítico de Caçapava do Sul, RS. Revista Brasileira de Geociências, 19(2): 153-169.

NARDI, L.V.S. \& HARTMANN, L.A. 1979. O Complexo Granulítico Santa Maria Chico do Escudo Sul-riograndense. Acta Geológica Leopoldensia, 3(6):45-76.

NYBLADE, A. A. \& POLLACK, H. N. 1992. A gravity model for the lithosfere in western Kenya and northeastern Tanzania. Tectonophysics, 212:257-267.

PORCHER, C.C. \& FERNANDES, L.A.D. 1990. Relações embasamento/ cobertura na porção ocidental do Cinturão Dom Feliciano: um esboço estrutural. Pesquisas, 17:72-84.

PORCHER C.C. 1992. Caracterização das condições defluxo em uma zona de cisalhamento tangencial na região de Santana da Boa Vista (RS). Porto Alegre. 192 p. (Dissertação de Mestrado em Geociências, Universidade Federal do Rio Grande do Sul).

PORCHER,C.C; FERNANDES, L.A.D. \& MONTEIRO, A.0.1995. Zonamento metamórfico das granadas e dados de geotermometria dos metamorfitos Cerro do Facão -Suíte Metamórfica Porongos (RS). IN: SIMPÓSIO NACIONAL DE ESTUDOS TECTÔNICOS, 5. Gramado, 1995. Boletim de resumos Expandidos... Gramado, SBG. p.69-70.

RAMGRAB, G.E.; WILDNER, W.; CAMOZZATO, E. (organiz.). 1995. Mapa Geológico da Folha de Porto Alegre (SH 22-Y-B / 1:250.000). PLGB/CPRM, Brasília, (no prelo).

RAMOS,V.A. 1988. Late Proterozoic-Early Paleozoic of South America - a Collisional History. Episodes, 11:168-174

REMUS, M.V.D. 1990. Geologia e geoquímica do Complexo Cambaizinho, São Gabriel (RS). Porto Alegre. 267p. (Dissertação de Mestrado, Universidade Federal do Rio Grande do Sul).

REMUS, M.V.D; MCNAUGHTON, N.J; HARTMANN, L.A.; GROVES, D.I. 1995. The oldest magmatic rock from the São Gabriel Block of the Sul-riograndense Shield, Southern Brazil, identified by $\mathrm{U} / \mathrm{Pb}$ dating of zircons using SHRIMP. IN: AUSTRALIAN CONFERENCE ON GEOCHRONOLOGY AND ISOTOPE SCIENCE., Perth, 1995. Extended Ahstracst... Perth, p.l.

RIBEIRO, M. \& FANTINEL, L.M. 1978. Associações petrotectônicas do Escudo Sul-riograndense: I Tabulação e distribuição das associações petrotectônicas do Escudo do Rio Grande do Sul. Iheringia, Série Geológica, 5:19-54.

SANTOS, E.L.; RAMGRAB, G.E.; MACIEL, L.A.; MOSMANN, R. 1989. Mapa Geológico do Estado do Rio Grande do Sul. DNPM, $1^{\circ}$ Distrito Regional.

SILVA P, B.C. 1984. Geology ofthe Polyphase deformed Precambrian Terrane of the Vila Nova Region, State of Rio Grande do Sul, Southern Brazil. Part I: Petrogenesis. Acta Geológica Leopoldensia, 17:35-152.

SUBRAHMANYAM, C. \& VERMA, R. K. 1982. Gravity interpretation of the Dharwar Greenstone-gneiss-granite terrain in the southern Indian shield and its geological implications. Tectonophysics, 84: 225-245.

SUBRAHMANYAM, C. 1978. On the relation of gravity anomalies to geotectonics ofthe Precambrian terrains ofthe south Indian Shield. J. Geol. Soe. india, 19(6): 251-263.

THOMAS, M. D.; GR1EVE, R.A.F.; SHARPTON, V. L. 1988. Gravity domains and assembly of the North American continent by collisional tectonics. Nature, 331: 28 .

TOMMASI, A \& FERNANDES, L.A.D. 1990. O ciclo brasiliano na porção sudeste da Plataforma Sul-americana: um novo modelo. IN: CONGRESSO URUGUAYO DE GEOLOGIA, 1. Montevideo, 1990. Anais... Montevideo, v.1, p. 107-114

TOMMASI, A.; FERNANDES, L.A.D; PORCHER, C.C.; VAUCHEZ, A. 1992. Evolução cinemática das porções internas do Cinturão Dom Feliciano na região de Piratini, RS. Pesquisas, 19(2):145-156.

UFRGS 1994. Mapeamento Geológico de parte das folhas de Capané e Passos das Canas. Trabalho de Graduação do Curso de Geologia, Instituto de Geociências da Universidade Federal do Rio Grande do Sul, Porto Alegre.

WELLMAN, P. 1988. Development ofthe australian proterozoic crust as inferred from gravity andmagnetic anomalies. Precambrian Research, 40/41:89-100.

WHITE, D. A., 1988. Application of regional gravity and magnetics to the regional geological framework of Austrália. IN: ASEG/SEG CONFERENCE. Adelaide, 1988 .
MANUSCRITO $\mathrm{N}^{\circ}$ A872B

Recebido em 31 de agosto de 1996 Revisão dos autores em 17 de março de 1997 Revisão aceita em 18 de março de 1997 